Letter to the Editor

\title{
Bilateral neurosensory retinal detachments secondary to ERK inhibitor use for metastatic lung adenocarcinoma
}

\author{
Vivian Kuang MBBS $^{1}$ \\ Robert CA Symons PhD FRANZCO ${ }^{1,2}$
}

1. Department of Ophthalmology, The Royal Melbourne Hospital, Parkville, VIC, 3050, Australia

2. Department of Surgery, The University of Melbourne, Parkville, VIC, 3010, Australia

Correspondence: Robert CA Symons, Level 4, Main Building, The Royal Melbourne Hospital, 300 Grattan Street, Parkville VIC 3050, Australia

Email: andrewsymons@gmail.com

Received 16 September 2018; accepted 20 September 2018

Conflict of interest: None

Funding sources: None

This is the author manuscript accepted for publication and has undergone full peer review but has not been through the copyediting, typesetting, pagination and proofreading process, which may lead to differences between this version and the Version of Record. Please cite this article as doi: 10.1111/ceo.13409

This article is protected by copyright. All rights reserved. 
Targeted immunotherapy for the treatment of solid tumours has progressed with many ongoing trials of novel anti-cancer therapies. Inhibitors of the Ras-RAFmitogen-activated kinase (MEK) kinase-extracellular signal-regulated kinase (ERK) pathway, in particular MEK inhibitors, have been associated with a number of ocular toxicities. ${ }^{1}$ We describe a case of bilateral neurosensory retinal detachment after commencement of an ERK inhibitor for metastatic lung cancer.

A 64 year-old Caucasian female with metastatic KRAS mutant non-small cell lung adenocarcinoma was enrolled in a Phase $1 \mathrm{~b}$ clinical trial of an ERK inhibitor (LTT462 $300 \mathrm{mg}$ orally daily) in combination with a pan-RAF inhibitor (LXH254 200mg orally daily). She had a past ocular history of hyperopia, right esotropia and mild amblyopia.

At baseline examination one week prior to commencing therapy, her best corrected visual acuities were 6/7.5 and 6/4.8 in the right and left eyes respectively. Ocular examination including macular and retinal vascular evaluation was normal. Optical coherence tomography (OCT) of the maculae and retinal nerve fibre layers were also normal.

The patient presented four days after commencing trial medications with painless bilateral central metamorphopsia and photopsia. Visual acuities were 6/12 in the right eye and 6/7.5 in the left eye. Examination revealed bilateral neurosensory detachment of the maculae accompanied by cystoid macular oedema (CMO) surrounding the fovea. Peripheral retinal examination was unremarkable bilaterally. OCT imaging showed bilateral sub macular fluid and CMO (Figure 1A). Autofluorescence imaging showed hypoautofluorescence at the inferior margins of the neurosensory detachments bilaterally and subtle changes consistent with CMO (Figure 1B). Both trial medications were ceased. 
Figure 1: A) OCT imaging showing neurosensory retinal detachment with subretinal fluid and CMO bilaterally. Central foveal thickness measures 539microns and 531microns in right and left eyes, respectively. B) Autofluorescence imaging demonstrating $\mathrm{CMO}$ and hypoautofluorescence at inferior margins of macular detachment.

One week later, ocular symptoms had resolved with recovery of visual acuities to 6/9 and $6 / 6$ in the right and left eyes respectively. Fundal evaluation and OCT findings showed resolution of all signs (Figure 2A). Autofluorescence showed persistent hypo autofluorescence along the inferotemporal arcades (Figure 2B).

Figure 2: A) OCT imaging demonstrates normalisation of retinal changes shown in Figure $1 \mathrm{~A}$. B) Autofluorescence imaging showing persistent hypo autofluorescence at inferior margin of detachment.

The Ras-RAF-mitogen-activated kinase (MEK) kinase-ERK pathway is one of many mitogen-activated protein kinase pathways (MAPK) involved in fundamental cellular processes including cellular proliferation, differentiation and survival. ${ }^{2}$ Mutations in BRAF and KRAS genes leading to preferential hyperactivation of this MAPK pathway are frequently involved in oncogenesis, including many cases of lung cancer. ${ }^{3}$ ERK $1 / 2$ is directly downstream of MEK $1 / 2$ in the phosphorylation cascade. ${ }^{2}$

Maculopathies including including bilateral neurosensory retinal detachment distinct from classic central serous chorioretinopathy secondary to the use of MEK inhibitors have been well described. ${ }^{1,4,5}$ Fluorescein angiography in two reported patients with MEK inhibitor-associated retinopathy has shown a lack of fluorescein leakage. ${ }^{4}$ The mechanism of MEK inhibitor maculopathy is poorly understood. 
Macular neurosensory retinal detachments have not been described in association with RAF inhibitors alone. ${ }^{5}$ Furthermore, ERK is more closely related to MEK in the MAPK pathway. Therefore, the complication described here was more likely secondary to the use of the ERK inhibitor rather than the pan-RAF inhibitor. However, we cannot exclude this as a possibility.

The case presented here showed a greater degree of macular detachment than seen with patients in our institution with MEK inhibitor-associated retinopathy.

To the best of our knowledge, there have been no previously published case reports in the literature describing bilateral neurosensory retinal detachment associated with ERK inhibitor use. However, one such case has been presented (Bakri SJ, American Society of Retina Specialists, Vancouver, July 2018).

\section{REFERENCES}

1. Francis $\mathrm{JH}$, Habib LA, Abramson $\mathrm{DH}$, et al. Clinical and morphologic characteristics of MEK inhibitor-associated retinopathy. Ophthalmology 2017;124(12):1788-98.

2. Yap JL, Worlikar S, MacKerell A, Shapiro O, Fletcher S. Small molecule inhibitors of the ERK signalling pathway: towards novel anti-cancer therapeutics. ChemMedChem 2011;6(1):38-48.

3. Ji J, Wang Z, Perera SA, et al. Mutations in BRAF and KRAS converge on activation of the mitogen-activated protein kinase pathway in lung cancer mouse models. Cancer Res 2007;67:4933-9. 
4. McCannel TA, Chmielowski B, Finn RS, et al. Bilateral subfoveal neurosensory retinal detachment associated with MEK inhibitor use for metastatic cancer. JAMA Ophthalmo/ 2014;132(8):1005-9.

5. Stjepanovic N, Velazquez-Martin JP, Bedard PL. Ocular toxicities of MEK inhibitors and other targeted therapies. Ann Onco/2016;27(6):998-1005. 


\section{University Library}

\section{- M I N E R VA \\ A gateway to Melbourne's research publications}

Minerva Access is the Institutional Repository of The University of Melbourne

Author/s:

Kuang, V;Symons, RCA

Title:

Bilateral neurosensory retinal detachments secondary to extracellular signal-regulated kinase inhibitor use for metastatic lung adenocarcinoma

Date:

2019-03-01

\section{Citation:}

Kuang, V. \& Symons, R. C. A. (2019). Bilateral neurosensory retinal detachments secondary to extracellular signal-regulated kinase inhibitor use for metastatic lung adenocarcinoma. CLINICAL AND EXPERIMENTAL OPHTHALMOLOGY, 47 (2), pp.297-299. https:// doi.org/10.1111/ceo.13409.

Persistent Link:

http://hdl.handle.net/11343/284788 